\title{
Positive Psychology and Its Relation to Salutogenesis
}

\author{
Stephen Joseph and Shifra Sagy
}

\section{Introduction}

The advent of contemporary positive psychology can be traced back to Martin E.P. Seligman's Presidential Address in 1999 to the American Psychological Association (APA). In that address he told his own story of changing direction. Following a moment of epiphany when gardening with his daughter Nikki, he realised that psychology had largely neglected the latter two of its three pre-World War II missions: curing mental illness, helping all people to lead more productive and fulfilling lives and identifying and nurturing high talent. With this realisation, Seligman resolved to use his APA presidency to initiate a shift in psychology's focus towards a more positive psychology (Seligman, 2004). This presidential initiative was catalysed through a series of meetings with both junior and senior scholars who would become the leading voices of the new positive psychology movement, and who began to map out what they saw as a positive psychology research agenda. This was followed by the hugely influential January 2000 special issue of the American Psychologist on positive psychology in which Seligman and Csikszentmihalyi (2000) wrote:

The aim of positive psychology is to begin to catalyze a change in the focus of psychology from preoccupation only with repairing the worst things in life to also building positive qualities. (Seligman \& Csikszentmihalyi, 2000, p. 5)

This chapter is a reprint of work published in Mittelmark, M.B., Sagy, S., Eriksson, M., Bauer, G., Pelikan, J.M., Lindström, B., \& Espnes, G.A. (eds). (2017). The Handbook of Salutogenesis. Springer, Cham. DOI: https://doi.org/10.1007/978-3-319-04600-6.

S. Joseph $(\bowtie)$

School of Education, University of Nottingham, Nottingham, UK

e-mail: Stephen.joseph@nottingham.ac.uk

S. Sagy

Martin Springer Center for Conflict Studies, Ben-Gurion

University of the Negev, Be'er Sheva, Israel
That special issue provided a broad vista of topics that were deemed to be covered under the positive psychology umbrella and included articles on happiness, individual development, subjective well-being, optimism, self-determination theory, adaptive mental mechanisms, emotions and health, wisdom, excellence, creativity, giftedness and positive youth development. From these beginnings over 20 years ago, positive psychology has flourished.

\section{Positive Psychology and Salutogenesis}

The positive psychology movement has produced new conceptual frameworks, instruments to measure human strengths and increased interest in topics such as optimism, hope, locus of control, creativity, self-esteem, emotional intelligence, empathy, humour and gratitude (Linley et al., 2006; Lopez \& Snyder, 2003). Positive psychologists have also endeavoured to apply this new work in educational, health and workplace contexts (Joseph, 2015a). Moreover, community researchers and public policy planners have suggested transforming positive psychology from an individual level to a societal level as well (Pavot \& Diener, 2004).

However, despite the feeling of innovation, it has also become clear that positive psychology has had a much longer past and might even be traced back to the origins of psychology itself, like William James' writings on 'healthy mindedness' (James, 1902). Positive psychology also shares a common heritage with parts of humanistic psychology and the writings of Abraham Maslow and Carl Rogers, in particular. These alternative beginnings to positive psychology are now well recognised (Robbins, 2015). However, much less well acknowledged in positive psychology is the heritage of the salutogenic paradigm first suggested by Antonovsky in his book Health, Stress and Coping (Antonovsky, 1979).

At first glance, it would seem that the relatively new field of positive psychology had much in common with the earlier approach of salutogenesis. Interestingly, however, the concept of salutogenesis has received relatively little attention 
within the positive psychology literature. For example, in the 2004 edition of Positive Psychology in Practice (Linley \& Joseph, 2004), there was no reference to salutogenesis in the book's subject index. Likewise, in the textbook A Primer in Positive Psychology (Peterson, 2006), it is similarly not indexed. There are exceptions - such as in Csikszentmihalyi and Csikszentmihalyi's (2006) edited book A Life Worth Living: Contributions to Positive Psychology - where a reference to salutogenesis comes half way through the book in the chapter by Antonella Delle Fave of the University of Milan on subjective experience and quality of life (Delle Fave, 2006). Delle Fave briefly notes the salutogenic approach. So it is not that the concept of salutogenesis has been invisible to positive psychologists, but rather that it has not achieved prominence as a framework for theory and research. How can this lack of attention to the concept of salutogenesis be explained? Our answer might be that the salutogenic theory originated in a different discipline than psychology: in medical sociology and - although subsequent applications have been more widespread - the concept has never been fully embraced by psychologists. Nonetheless, there are clear conceptual similarities between Antonovsky's ideas and some of those developed by the positive psychologists (Lutz, 2009).

In this chapter, however, we attempt to reflect on the conceptualisation of positive psychology in light of Antonovsky's theory of salutogenesis. Furthermore, we consider how Antonovsky's core concept, the sense of coherence, provides a new framework for understanding the operation of positive psychology constructs.

Both positive psychology and the salutogenic paradigm challenged mainstream thought about the pathological focus of sociology in the 1970s and psychology in the 2000s, respectively, to consider the resources of healthy functioning. In this regard, both approaches seem to be adopting the same view. However, there was a difference between the two approaches. As clinical psychology had traditionally adopted diagnostic language and a focus on pathology, positive psychology turned its attention to the normal category and positive functioning, and by doing so implicitly condoned the dichotomy between the normal and the abnormal (Joseph \& Linley, 2006). Antonovsky's salutogenesis paradigm, on the other hand, offered a new definition of the ease-dis-ease continuum in the medical discipline, thus dissolving the dichotomy between illness and wellness (Antonovsky, 1979).

The argument of positive psychology was that insufficient attention had been paid to the positive side of human experience. The weight of psychological research had been on pathological functioning. This led researchers to turn their attention to strengths of character, talents and abilities and what makes for a healthy and happy life. This new focus challenged the mainstream to shift its attention so that new research would be conducted alongside traditional research. As Folkman and Moskowitz (2003) said:

...those who advocate the study of positive aspects of psychology do not intend that it replace concern with its negative aspects. What appears to be an overemphasis may instead be indicative of a catch-up phase for an area that has been underemphasised in recent years. (Folkman \& Moskowitz, 2003, p. 121)

Such a position provided a clear vision for the investigation of the positive alongside the negative. Csikszentmihalyi (2003), referring to his and his collaborators' pioneering efforts, provided an argument for studying the positive relatively independently of the negative:

Basically, we intended to do our best to legitimize the study of
positive aspects of human experience in their own right-not
just as tools for prevention, coping, health, or some other desir-
able outcome. We felt that as long as hope, courage, optimism,
and joy are viewed simply as useful in reducing pathology, we
will never go beyond the homeostatic point of repose and begin
to understand those qualities that make life worth living in the
first place. (Csikszentmihalyi, 2003, pp. 113-114)

Positive psychology has since developed into a distinct discipline in its own right. There have been new handbooks, textbooks and dedicated university-level courses in positive psychology. In addition, there are now biannual positive psychology conferences held by the International Positive Psychology Association and the European Network for Positive Psychology, together with a host of conference themes and sections dedicated to positive psychology. As such, the momentum of the positive psychology movement seems to be directed towards deliberately studying wellbeing in and of itself. Despite this, there are some who have expressed concern that to separate the positive aspects of human experience from the negative may be counterproductive (e.g. Pauwels, 2015).

What is potentially more valuable is to understand the relations between the positive and the negative, comprehending that the role of positive psychology should be to transform how we conceptualise human experience.

Indeed, the idea that human experience can be divided into positive and negative is problematic and the use of such terminology unhelpful. Some scholars have explicitly called for the integration of the positive and negative through the application of more humanistic ways of thinking (Joseph, 2015b). In this way, such a positive psychology could transform the agenda of mainstream psychology by looking for ways to dissolve the boundaries between the positive and the negative. In contrast, the danger of positive psychology now is that its existence serves to condone the separation of the positive and the negative. Thus, rather than serving as a transformational force, it maintains the status quo. Seen this way, it seems misleading to talk of positive psychology as challenging the mainstream pathological agenda of psychology. Moreover, by focusing on positive experiences only, it sends out a con- 
tradictory message that the positive is separable from the negative, and while worth studying in its own right, the necessity remains for disciplines of psychology committed to the negative. Thus, ironically, positive psychology strengthens the dichotomy between the positive and the negative.

In light of the above discussion of how it is problematic to think of human experience as either positive or negative, it becomes clear then that the concept of salutogenesis offers an alternative basic theory and conceptual framework. In his proposal, Antonovsky (1979) claims that health and illness should be viewed not as a dichotomy but as a continuum. Human environments by their very nature are stressor-rich, whether microbiological, personal, economic, social or geopolitical. As such, the human being inhabits a world in which it is impossible to avoid stressors and the normal state of the human organism is one of entropy, disorder and disruption of homeostasis.

The basic philosophical assumption of the salutogenic theory is that, instead of perceiving the human system as one which is sound unless it is attacked by some pathogen, the human system is viewed as basically unsound, continuously attacked by disturbing processes and elements which cannot be prevented. This basic assumption is different than the basic philosophical premises of much positive psychology.

Salutogenesis challenges the dominant pathogenic paradigm, but in a different way than the positive psychology movement. Rather than thinking about people as either healthy or diseased, it opens the way for thinking about health and disease along a continuum that goes from 'health ease' to 'dis-ease'. In such an approach, no one is categorised as healthy or diseased. All people are somewhere between the imaginary poles of total wellness and total illness. Even the fully robust, energetic, symptom-free, richly functioning individual has the mark of mortality: he/she wears glasses, has moments of depression, comes down with flu and may also have as yet non-detectable malignant cells. Even the terminal patient's brain and emotions may be fully functional. The great majority of us are somewhere between the two poles. Priority in service is justly given to those at the sicker end of the continuum, but all persons become the focus for research and intervention. Wherever they are on the continuum, there is the possibility of further movement towards the healthy pole.

Moreover, assuming that stressors are ubiquitous, and that there is a continuum of ease-dis-ease, our focus shifts from asking how to eradicate this or that stressor to how to facilitate becoming healthier. Thus, salutogenesis offers a brand new challenge to positive psychology to rethink its stance in relation to the negative. It might suggest that positive psychology consider the implementation of its concepts at all points along the spectrum of dis-ease to well-being. To deepen this direction, we turn to Antonovsky's concept of sense of coherence (SOC).

\section{Sense of Coherence and Positive Psychology}

Positive psychologists may be more familiar with the SOC concept than with the broader salutogenic theory itself. However, many of them misunderstand it as a personality disposition or as a coping style. Actually, the concept of SOC has been developed as a concept on a higher level of abstraction, as a worldview. It provides us with a powerful concept to predict health (Eriksson \& Lindström, 2011), but yet underutilised. What positive psychology still misses is a theoretical framework for understanding how the range of positive psychological variables, such as optimism, gratitude, forgiveness, curiosity and others, that are routinely studied as predictors of health and happiness exert their effect.

It has become apparent in positive psychology that although some concepts seem to be more generally thought of as 'positive' than others, whether or not any such factor is related to well-being depends on the context. To illustrate, a trait such as optimism is generally considered a psychological ingredient that contributes to well-being. It may be that optimistic people are better able to cope with stress, for example. So, in a stressful context, optimism plays a beneficial moderating role. But, in another context, it could be that optimism impedes well-being. For example, more optimistic people may adopt more reckless investment strategies. As such, it is likely that many psychological traits and processes are neither inherently positive nor negative, but only positive or negative in their effect with regard to specific circumstances.

On a different level of abstraction, SOC refers not to a special set of traits or coping strategies but rather to the mediational mechanism through which all other factors exert their influence on health and well-being. Personal and social resources can build comprehensibility, manageability and meaningfulness of any given situation, allowing us to cope with the ubiquitous stressors of life, thus promoting wellbeing in the never-ending struggle against entropy. On the other hand, those factors that make demands on comprehensibility, manageability and meaningfulness leave us vulnerable to the effects of entropy.

Regarding the development of SOC, Antonovsy (1987) suggested that at a certain age (30 years), people have developed a fairly consistent SOC, although recent studies suggest that unexpected traumatic events can challenge our SOC, requiring us to rebuild a new SOC in light of our experiences (Antonovsky \& Sagy, 1986; Bental-Israeli \& Sagy, 2010).

In the past two decades, positive psychology has fuelled interest in post-traumatic growth (Joseph, 2011). Posttraumatic growth is a wide-ranging concept, still in development, but to date three broad domains of positive change have been noted that best describe the ways people often report that they have been changed following trauma. Firstly, relationships are enhanced in some way. For exam- 
ple, people describe that they come to value their friends and family more, feel an increased sense of compassion for others and a longing for more intimate relationships. Secondly, people change their views of themselves in some way, for example, that they have a greater sense of personal resiliency, wisdom and strength, perhaps coupled with a greater acceptance of their vulnerabilities and limitations. Thirdly, people describe changes in their life philosophy, for example, finding a fresh appreciation for each new day and reevaluating their understanding of what really matters in life.

Positive changes are widely reported by people following trauma. Using psychometric measures and open-ended interviews, a large number of studies have shown that growth is commonly reported by survivors of various traumatic events, including transportation accidents (shipping disasters, plane crashes and car accidents), natural disasters (hurricanes and earthquakes), interpersonal experiences (combat, rape, sexual assault and child abuse), medical problems (cancer, heart attack, brain injury, spinal cord injury, HIV/AIDS, leukaemia, rheumatoid arthritis, multiple sclerosis and illness) and other life experiences (relationship breakdown, parental divorce, bereavement and immigration). Typically, 30-70\% of survivors will say that they have experienced positive changes of one form or another (Joseph, 2011).

Moreover, research indicates that greater post-traumatic growth is associated with personality factors such as emotional stability, extraversion, openness to experience, optimism and self-esteem; ways of coping such as acceptance, positive reframing, seeking social support, turning to religion, problem solving; and social support factors (Joseph, 2011). Such a framework can be applied with the aim of understanding how positive psychological constructs may be beneficial, but the area where this framework seems most clearly applicable is in how people overcome and grow personally following adversity.

\section{A Salutogenic Positive Psychology}

The aim of this chapter is to promote bridge building between the paradigm of salutogenesis and the movement of positive psychology, and to suggest a joint conceptual framework of salutogenic positive psychology. We trust that despite the differences between the two paradigms, an integrative approach could contribute to deeper understanding of both approaches.

One contribution of the integrative approach relates to the role of sociological factors in explaining SOC development as well as other positive psychological concepts. In contrast to the common purely positive psychological view, Antonovsky $(1991,1993)$ attempted, within a systems theory framework, to analyse how social structures shape the strength of the SOC. He claimed that to disregard the power of history, the generational experiences of the macro-political events of war and depression, population shifts and revolutions are to disregard the context within which the strength of each of us is shaped. Indeed, early socialisation has been discussed in psychological theories, and experiences in the family have been considered as crucial. But these experiences are themselves shaped by the broader social structure which is usually ignored. Socioeconomic status and educational levels have been shown to be important factors in building strong SOC (Madarasova Geckova et al., 2010; Sagy \& Antonovsky, 2000).

The implication of these analyses for salutogenically oriented clinicians could lead to interventions such as active participation in transforming environmental conditions. It certainly seems reasonable to hypothesise that one who sees life as comprehensible, manageable and meaningful is more likely to optimally exploit potential resistance resources. This approach can also help us to theoretically explain why some prevention programmes or health promotion plans tend to work well for some people but not as well for others (Sagy, 2014). Evidence from factor analysis suggests that SOC and well-being, although associated, are distinct constructs (Cilliers \& Coetzee, 2003).

As such, we envisage that the relationship between wellbeing and commonly studied positive psychological constructs such as optimism, gratitude, forgiveness and hope is mediated by SOC. When this has been tested, the evidence is supportive (Lambert et al., 2009). But SOC is also influenced by life experiences and social systems, such that well-being is ultimately the product of trauma and other life events, positive psychology factors and the social structure. However, in each case, the relationship with well-being is mediated by SOC (see Fig. 23.1). Moreover, the possibility exists that each of these relationships is moderated by the other factors, such that, for example, positive psychological factors are only related to well-being in specific social structures or at particular levels of trauma.

Returning to the concept of posttraumatic growth, the salutogenic positive psychology framework could contribute especially well to the understanding of traumatic experience by the interaction of a variety of concepts related to personality, tendencies and strategies of coping together with sociological factors. These different factors could, for example, jointly predict post-traumatic growth, while the SOC could be the mediator/moderator in these interactions. For example, one line of investigation has been to study SOC in therapists who work traumatised clients, showing that those with higher SOC report more positive changes (Linley et al., 2005) and less compassion fatigue and burnout (Linley \& Joseph, 2007).

From Fig. 23.1, one can hypothesise that trauma has a shattering effect on the person's SOC resulting in a process of breakdown of these foundational perceptions. It is though 
Fig. 23.1 The relationship between positive psychology constructs and well-being is hypothesised to be mediated by SOC

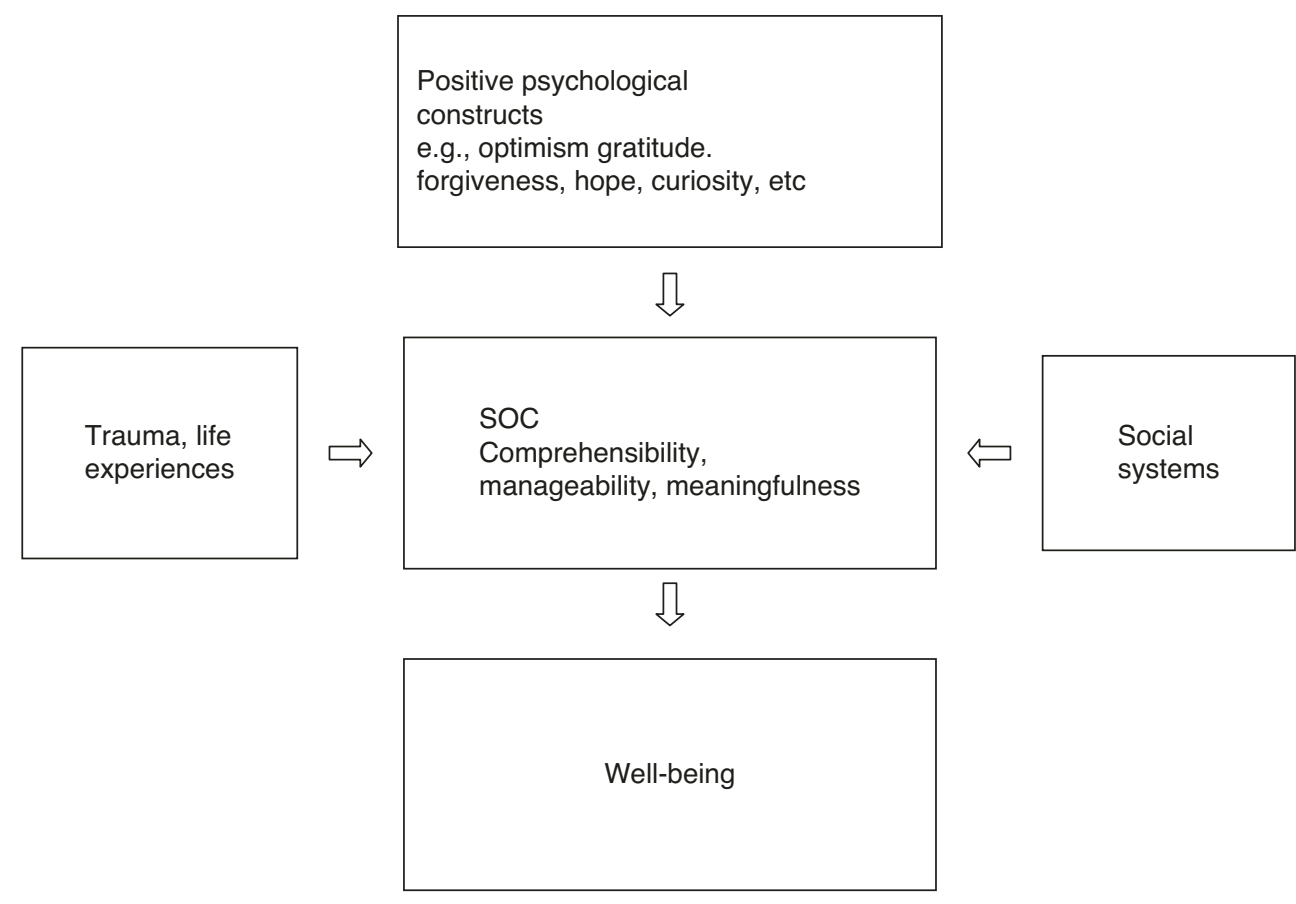

the influence of social systems external to the person and the development of positive qualities within the person that SOC can be re-established - but in ways that are accommodating of the changed circumstances. This process resulting in increased psychological well-being is post-traumatic growth.

Thus, we can view post-traumatic growth as a description of those positive changes that arise through the resolution and rebuilding of the person's SOC and the resultant posttraumatic distress that this process entails. The salutogenic positive psychology perspective allows us to develop an understanding of potential traumatic experiences which integrates post-traumatic distress and post-traumatic growth within a single conceptual framework. This new integrative perspective could also guide clinical practice to develop interventions which promote SOC amongst trauma survivors.

Our point is that SOC offers not so much an additional set of variables alongside those already studied by positive psychologists, but a larger theoretical framework within which to consider the operation of these variables. As others have also argued, SOC can be seen as an inclusive concept (Almedom, 2005).

\section{Conclusion}

It appears that despite their different theoretical roots, the integration of the two paradigms - salutogenesis and positive psychology - has stronger explanatory power in promoting health and well-being. We trust that positive psychologists will benefit from a deeper appreciation of the SOC construct in two ways: firstly, understanding how social structures shape the strength of SOC, and secondly, how SOC provides the cognitive mechanisms within the individual that mediates the relationship between positive psychology constructs such as hope, optimism, gratitude and well-being. Finally, there are two ways in which salutogenic researchers can benefit from positive psychology. Firstly, positive psychology offers a new and evidence-based means for putting salutogenesis into practice at both micro- and macro levels. However, the second and most important contribution of positive psychology is in reminding salutogenic researchers that their evaluation of outcomes related to SOC need not be pathological. We need to move beyond outcomes such as the absence of depression, reduction in hostility and the like, to include the presence of happiness, development of empathy and more. In this way, we begin to see greater convergence between the two disciplines and the emergence of salutogenic positive psychology.

\section{References}

Almedom, A. M. (2005). Resilience, hardiness, sense of coherence, and posttraumatic growth: All paths leading to "light at the end of the tunnel"? Journal of Loss and Trauma, 10(3), 253-265.

Antonovsky, A. (1979). Health, stress, and coping. Jossey-Bass.

Antonovsky, A. (1991). The salutogenic approach to family system health: Promise and danger. European congress on "mental health in European families." Retrieved from http://angelfire.com/ok/soc/agolem.html.

Antonovsky, A. (1993). The structure and properties of the sense of coherence scale. Social Science and Medicine, 36, 725-733.

Antonovsky, H., \& Sagy, S. (1986). The development of a sense of coherence and its impact on responses to stress situations. The Journal of Social Psychology, 126, 213-225. 
Antonovsy, A. (1987). Unravelling the mystery of health. How people manage stress and stay well. Jossey-Bass.

Bental-Israeli, A., \& Sagy, S. (2010). Life experiences contributing to the development of a sense of coherence: Consistency and/or breakthrough experience. Studies in education, 1, 215-241. Hebrew.

Cilliers, F., \& Coetzee, S. C. (2003). The theoretical-empirical fit between three psychological wellness constructs: Sense of coherence, learned resourcefulness and self-actualisation. South African Journal of Labour Relations, 27(1), 4-24.

Csikszentmihalyi, M. (2003). Legs or wings? A reply to R. S. Lazarus. Psychological Inquiry, 14, 113-115.

Csikszentmihalyi, M., \& Csikszentmihalyi, I. S. (Eds.). (2006). A life worth living: Contributions to positive psychology. Oxford University Press.

Delle Fave, A. (2006). The impact of subjective experience on the quality of life: A central issue for health professionals. In M. Csikszentmihalyi \& I. S. Csikszentmihalyi (Eds.), A life worth living: Contributions to positive psychology (pp. 165-181). Oxford University Press.

Eriksson, M., \& Lindström, B. (2011). Life is more than survival: Exploring links between Antonovsky's salutogenic theory and the concept of resilience. In K. M. Gow \& M. J. Celinski (Eds.), Wayfinding through life's challenges: Coping and survival (pp. 31-46). Nova.

Folkman, S., \& Moskowitz, J. T. (2003). Positive psychology from a coping perspective. Psychological Inquiry, 14, 121-125.

James, W. (1902). The varieties of religious experience: A study in human nature. Longman, Green.

Joseph, S. (2011). What doesn't kill us: The new psychology of posttraumatic growth. Basic Books.

Joseph, S. (Ed.). (2015a). Positive psychology in practice: Promoting human flourishing in work, health, education, and everyday life. Wiley.

Joseph, S. (2015b). The future of positive psychology in practice. In S. Joseph (Ed.), Positive psychology in practice: Promoting human flourishing in work, health, education, and everyday life (pp. 823828). Wiley.

Joseph, S., \& Linley, P. A. (2006). Positive psychology versus the medical model?: Comment. American Psychologist, 61, 332-333.

Lambert, N. M., Graham, S. M., Fincham, F. D., \& Stillman, T. F. (2009). A changed perspective: How gratitude can affect sense of coherence through positive reframing. The Journal of Positive Psychology, 4(6), 461-470.
Linley, A. P., \& Joseph, S. (Eds.). (2004). Positive psychology in practice. Wiley.

Linley, P. A., \& Joseph, S. (2007). Therapy work and therapists' positive and negative well-being. Journal of Social and Clinical Psychology, 26(3), 385-403.

Linley, A. P., Joseph, S., Harrington, S., \& Wood, A. M. (2006). Positive psychology: Past, present, and (possible) future. The Journal of Positive Psychology, 1, 3-16.

Linley, P. A., Joseph, S., \& Loumidis, K. (2005). Trauma work, sense of coherence, and positive and negative changes in therapists. Psychotherapy and Psychosomatics, 74(3), 185-188.

Lopez, S. J., \& Snyder, C. R. (Eds.). (2003). Positive psychological assessment: A handbook of models and measures. American Psychological Association.

Lutz, J. (2009). Flow and sense of coherence: Two aspects of the same dynamic? Global Health Promotion, 16(3), 63-67.

Madarasova Geckova, A., Tavel, P., van Dijk, J. P., Abel, T., \& Reijneveld, S. A. (2010). Factors associated with educational aspirations among adolescents: Cues to counteract socioeconomic differences? BMC Public Health, 10, 154-163.

Pauwels, B. G. (2015). The uneasy-And necessary-Role of the negative in positive psychology. In S. Joseph (Ed.), Positive psychology in practice: Promoting human flourishing in work, health, education, and everyday life. Wiley.

Pavot, W., \& Diener, E. (2004). Findings on subjective Well-being: Applications to public policy, clinical interventions, and education. In P. A. Linley \& S. Joseph (Eds.), Positive psychology in practice (pp. 679-692). Wiley.

Peterson, C. (2006). A primer in positive psychology. Oxford University Press.

Robbins, B. D. (2015). Building bridges between humanistic and positive psychology. In S. Joseph (Ed.), Positive psychology in practice: Promoting human flourishing in work, health, education, and everyday life (pp. 31-46). Wiley.

Sagy, S. (2014). Preventing drug abuse among children and adolescents: Where does the salutogenic approach direct us? Health, 6, 541-548.

Sagy, S., \& Antonovsky, H. (2000). The development of the sense of coherence: A retrospective study of early life experiences in the family. International Journal of Aging \& Human Development, 51, 155-166.

Seligman, M. E. P. (2004). Foreword. In P. A. Linley \& S. Joseph (Eds.), Positive psychology in practice (pp. xi-xiii). Wiley: Hoboken.

Seligman, M. E. P., \& Csikszentmihalyi, M. (2000). Positive psychology: An introduction. American Psychologist, 55, 5-14.

Open Access This chapter is licensed under the terms of the Creative Commons Attribution 4.0 International License (http://creativecommons. org/licenses/by/4.0/), which permits use, sharing, adaptation, distribution and reproduction in any medium or format, as long as you give appropriate credit to the original author(s) and the source, provide a link to the Creative Commons license and indicate if changes were made.

The images or other third party material in this chapter are included in the chapter's Creative Commons license, unless indicated otherwise in a credit line to the material. If material is not included in the chapter's Creative Commons license and your intended use is not permitted by statutory regulation or exceeds the permitted use, you will need to obtain permission directly from the copyright holder.

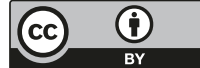

